\title{
Rekreasyon Alanlarında Ziyaretçi Tercihlerinin Sosyal Medya Verileri Kullanılarak Değerlendirilmesi: Ordu İli Örneği
}

\author{
Evaluation of Visitor Preferences on Recreation Areas by Using Social Media Data: \\ Case of Ordu Province (Turkey)
}

\author{
Mesut GÜZEL ${ }^{1}$ \\ Murat YEŞİL ${ }^{2}$
}

\author{
Araştırma Makalesi / Research Article \\ Geliș Tarihi / Received: 22. 03. 2021 \\ Kabul Tarihi / Accepted: 11. 05. 2021 \\ Doi: 10.48146/odusobiad.899693
}

Atıf / Citation: Güzel, M. ve Yeşil, M. (2021). "Rekreasyon Alanlarında Ziyaretçi Tercihlerinin Sosyal Medya Verileri Kullanılarak Değerlendirilmesi: Ordu İli Örneği, ODUSOBİA, 11(2), 437-450, doi: 10.48146/odusobiad.899693

\section{Öz}

Günümüzde sosyal medyada geçirilen zaman, insanların gündelik yașamının önemli bir bölümünü oluşturmaktadır. Sosyal medya, iletişim ve sosyalleşme işlevinin yanında her konuda çeşitli bilginin paylaşıldığı oldukça büyük bir veri kaynağıdır. Rekreasyon alanlarında ziyaretçi tercihlerinin belirlenmesine yönelik olarak birçok geleneksel yöntem izlenmesine karşın sosyal medya verilerinin bu amaçla kullanılması oldukça yeni bir olgudur. Çekildiği noktanın coğrafi konumu bilinen fotoğraflar ve sosyal medya platformlarında mekânlar ile ilgili yapılan yorumlar sayesinde, ziyaretçilerin tercih ve görüşleri ile ilgili önemli bilgiler elde edilmektedir. Bu bağlamda çalışmanın temel amacı; Ordu ili rekreasyon alanlarında ziyaretçi tercih ve eğilimlerinin sosyal medya verileri ıșığında incelenmesidir. Bu amaç doğrultusunda, ikisi kent ormanı ve ikisi tabiat parkı statüsünde dört rekreasyon alanı seçilmiştir. Bu alanlarla ilgili veriler dört sosyal medya platformundan toplanmıştır. Ardından, 2012 yılından günümüze dek konum belirtilerek paylaşılan 8.205 fotoğraf ve 2.646 yorum değerlendirilmiștir. Buna göre; incelenen dört rekreasyon alanı içinde sosyal medyada en fazla bilineni Ulugöl Tabiat Parkı'dır. Ayrıca rekreasyon alanlarında, özellikle yoğun kullanımın olduğu yaz aylarında fotoğraf paylaşımları artmakla beraber Ulugöl Tabiat Parkı'nda önemli bir sonbahar kullanımının bulunduğu da görülmüștür.

Anahtar Kelimeler Peyzaj mimarlığı, Rekreasyon, Ziyaretçi tercihleri, Sosyal medya, Ordu ili

\begin{abstract}
Time spent on social media today constitutes an important part of people's daily life. Social media is a very large data source that is shared in addition to its communication and socialization functions. Although many traditional methods are followed for determining visitor preferences in recreation areas, using social media data for this purpose is a new phenomenon. Thanks to the photographs whose geographical location of the point where it was taken are known and the comments made about the venues on social media platforms, important information about the preferences and opinions of the visitors are obtained. The main purpose of the study is to evaluate visitor preferences and tendencies in the recreation areas of Ordu in the light of social media data. For this purpose, four recreational areas, two of which have the status of urban forests and two of which are nature parks. Data on these areas were collected from the four social media platforms. Then, 8.205 photos and 2.646 comments shared by specifying the location since 2012 have been evaluated. According to this, among the recreational areas studied, the most well-known in social media is Ulugol Nature Park. Although photo sharing increases in recreation areas, especially in summer, it has been observed that there is also an important use of autumn in Ulugol Nature Park.
\end{abstract}

Keywords Landscape architecture, Recreation, Visitor preferences, Social media, Ordu province

\section{Giriş}

İnsan-doğa etkileşimlerini anlamada önemli bir bilgi kaynağı olarak karşımıza sosyal medya çıkmaktadır (Toivonen vd., 2019). Günümüzde yetişkin insanların \%74'lük büyük bir bölümünün

${ }^{1}$ Sorumlu Yazar, Arş. Gör., Ordu Üniversitesi Ziraat Fakültesi Peyzaj Mimarlığı Bölümü, Ordu, e-mail: mesutguzel@odu.edu.tr, ORCID ID: 0000-0001-6172-5812

2 Doç. Dr., Ordu Üniversitesi Ziraat Fakültesi Peyzaj Mimarlığı Bölümü, Ordu, e-mail: muratyesil@odu.edu.tr, ORCID ID: 00000002-3643-5626 
çevrimiçi sosyal paylaşım ağlarını kullandığı ifade edilmektedir (Wang, 2015). "We Are Social” adlı sosyal medya ajansına göre ise, 2020 Ocak ayı itibariyle Türkiye'de 54 milyon aktif sosyal medya kullanıcısı bulunmaktadır. Aynı ajansa göre Türkiye'de 37 milyon Facebook kullanıcısı, 38 milyon Instagram kullanıcısı ve 11.8 milyon Twitter kullanıcısı bulunmaktadır (We Are Social, 2021). Ceșitli turistik faaliyetlere ve gezilere katılan çok sayıda insan, seyahatleri boyunca çektikleri fotoğraf ve videoları yukarıda adı geçen sosyal medya platformları üzerinden tüm dünya ile açık bir şekilde paylaşmaktadır (Arat ve Dursun, 2016). Bunun yanı sıra gittikleri mekânların ilgi çekici özelliklerini, mekânla ilgili tavsiye ve şikâyetlerini sosyal medya aracllğıyla özgür bir şekilde dile getirebilmektedir. Bu yönüyle sosyal medya verileri, kullanıcıların ziyaret ettikleri mekânlarla ilgili tercih, beğeni ve eğilimlerini anlama noktasında oldukça önemlidir. Anket, gözlem vb. geleneksel yöntemlere bir alternatif ve tamamlayıcı unsur olarak sosyal medya içeriklerinin analiz edilmesi; korunan alanlar gibi doğa merkezli etkinliklerin gerçekleştirildiği alanlarda, ziyaretçilerin tercihlerini belirlemenin ve daha uzun zaman aralıklarında veri sağlamanın oldukça düşük maliyetli, aynı zamanda güvenilir bir yolu olarak kullanılmaktadır (Hausmann vd., 2018; Toivonen vd., 2019). Ayrıca bu tip bir veri toplama yöntemi, geleneksel yöntemlere oranla veri toplama süresini kısaltma olanağı sunmaktadır. Ziyaretçi tercihlerinin anlaşılmasında kullanılan geleneksel anket yöntemi ve bu yönteme oranla çok daha yeni bir yöntem olan sosyal medya içeriklerinin değerlendirilmesinin birlikte kullanılarak karşılaştırıldığı birtakım çalıșmalar yapılmıștır (Heikinheimo vd., 2017; WaldenSchreiner vd., 2018). Bu çalışmalarda geleneksel yöntemlerin uygulanmasında gereken insan gücü ve maliyet düşünüldüğünde sosyal medya verilerinin önemli bir alternatif olduğu görülmüştür. Ancak sosyal medyanın analiz edilmesinde ileri düzeyde yöntemlerin kullanımı şu an için oldukça sinırlıdır (Toivonen vd., 2019).

Kentlerde ve kent çevresinde yaşayan insanlar, zorlu kent yaşamının getirdiği stres halini bertaraf etmek ve tekdüzeliği kırmak adına serbest zamanlarını çeşitli rekreasyonel etkinliklere ayırmaktadır. Artan kent nüfusu ile birlikte çok daha fazla sayıda insan, kaliteli ve beklentilerini karşılayan rekreasyonel aktivitelere ihtiyaç duymaktadır. Bu nedenle korunan alanlar gibi çok çeşitli rekreasyon olanağı sunan alanlara talep her geçen gün artmaktadır. Yoğun ve plansız rekreasyonel faaliyetler sonucunda bu alanların taşıma kapasitesi aşılmakta ve hem kaynak değerleri zarar görmekte hem de ziyaretçilerin rekreasyon alanından memnuniyet düzeyleri azalmaktadır. Bu gibi problemlerin önlenebilmesi amacıyla, korunan alanlarda ziyaretçi yönetimine yönelik farklı araştırmacılar tarafından çeşitli modeller geliştirilmiştir (Göktuğ ve Kurkut, 2016). Bu modellere örnek olarak; Clark ve Stankey (1979) tarafından geliştirilen Rekreasyonel Fırsatların Dağılımı (ROS), Stankey ve arkadaşları tarafından 1985 yılında geliştirilen Kabul Edilebilir Değişim Sınırları (LAC), Ziyaretçi Deneyimini ve Kaynağı Koruma (VERP) ve Ziyaretçi Etki Yönetimi (VIM) verilebilir (Akten vd., 2012; Göktuğ ve Kurkut, 2016). Milli park, tabiat parkı ve kent ormanı gibi hassas bir koruma-kullanma dengesi üzerinde yönetilen alanlarda ziyaretçilerin beklenti ve tercihlerinin doğru belirlenmesi isabetli yönetim modellerinin yapılması ve insan-doğa ilişkisinin sınırlarının belirlenmesi noktasında önem arz etmektedir.

İnsan-doğa etkileșimlerindeki davranış kalıplarının mekânsal olarak analiz edilmesinde coğrafi işaretli (geotagged), lokasyonu bilinen sosyal medya verilerinin kullanıldı ̆̆ı çok sayıda çalışma vardır (Hausmann vd., 2018; Zhang vd., 2019; Sinclair vd., 2020). Coğrafi işaretli fotoğraflar ziyaretçi davranışlarının ve gerçekleştirilen aktivitelerin dağılımının görselleştirilmesinde oldukça etkili olmaktadır (Walden-Schreiner vd., 2018). Ayrıca kültürel ekosistem hizmetlerinin değerlendirilmesi gibi özelleşmiş konularda sosyal medya verilerinin kullanılması üzerine çalışmalar son yıllarda artış göstermiştir (Richards ve Friess, 2015; Figueroa-Alfaro ve Tang, 2017; Richards ve Tunçer, 2018; Arslan ve Örücü, 2020; Ghermandi vd., 2020). Korunan alanlar gibi doğa ve insan etkileşiminin en yoğun görüldüğü alanlar özelinde, ziyaretçi tercih ve eğilimlerinin belirlenmesinde sosyal medya içeriklerinin kullanıldığı çalışmalar, sosyal medyadan veri toplama yönteminin büyük ölçekli alanlara olan uygunluğunu açıkça ortaya koymaktadır (Tenkanen vd., 2017; Hausmann vd., 2018; Mancini vd., 2018; Walden-Schreiner vd., 2018; Öztürk vd., 2019).

Bu çalışmadaki sosyal medya verilerinin kaynağını Facebook, Instagram, Google Maps ve Foursquare içerikleri oluşturmaktadır. Bu platformların birçok ortak özelliği bulunduğu gibi birtakım özellikleri ile diğerlerinden ayrıldığı noktalar da bulunmaktadır. Örneğin; Instagram kullanıcıların fotoğraf yüklemesine, "filtre" adı verilen fotoğraf manipülasyonları ile fotoğrafların değiștirilmesine, bu fotoğrafların diğer Instagram kullanıcılarıyla paylaşılarak yorum ve beğeni yapılmasına olanak 
tanımaktadır (Lee vd., 2015). Mobil cihazlardan erişimin kolay olduğu ve fotoğraf paylaşımının pratik şekilde yapılabildiği bu platform, günümüzde genç yaşlı tüm insanların ilgi odağındadır. Bununla birlikte, Google Maps ve Foursquare platformları ise daha ziyade mekânların özellikleri ve kullanıcı yorumları ile ön plana çıkmaktadır.

Çalışmanın temel amacını Ordu ilindeki dört önemli rekreasyon alanında ziyaretçilerin alanları kullanmadaki zamansal ve fotoğraf çekim tercihleri, yaşadıkları olumlu ya da olumsuz deneyimler ile bu alanların sosyal medyadaki bilinirliğinin sosyal medya içerikleri kullanılarak değerlendirilmesi oluşturmaktadır. Bu amaç doğrultusunda, daha önce belirtilen sosyal medya platformlarında paylaşılan fotoğraflar ve yorumlar derlenmiştir. Bu veriler ışığında; rekreasyon alanlarının sosyal medya platformlarındaki popülaritesi, rekreasyon alanlarının ziyaret edilmesinde zamansal tercihler, fotoğraf çekim tercihleri, paylaşılan fotoğraflarda ön plana çıkan unsurlar ve ziyaretçilerin alanlarla ilgili beğeni ve şikâyetleri ortaya konulmuştur.

\section{Materyal ve Yöntem}

Araștırma alanı olarak Karadeniz Bölgesi'nde bulunan Ordu ili ve ildeki bazı rekreasyon alanları seçilmiştir (Görsel 1). Ordu iline 2013 yılında büyükşehir statüsü verilmesi ile hızlı bir kentleşme ve arazi kullanım değişikliği ortaya çıkmıştır. Bunun sonucu olarak Ordu ilinin nüfusu geçen zaman içerisinde önemli oranda artış göstermiştir. Adrese Dayalı Nüfus Kayıt Sistemi'ne göre 2000 yılında 705.746 olan il nüfusu geçen 20 yll içerisinde 761.400'e yükselmiştir (TÜIK, 2021). Artan nüfusun rekreasyon ihtiyacını karşılayabilecek nitelikli kentsel ve kırsal alanların sağlanması, bu alanların yönetilmesi ve beklentiyi karşılaması sağlıklı toplum için vazgeçilmez bir unsurdur.

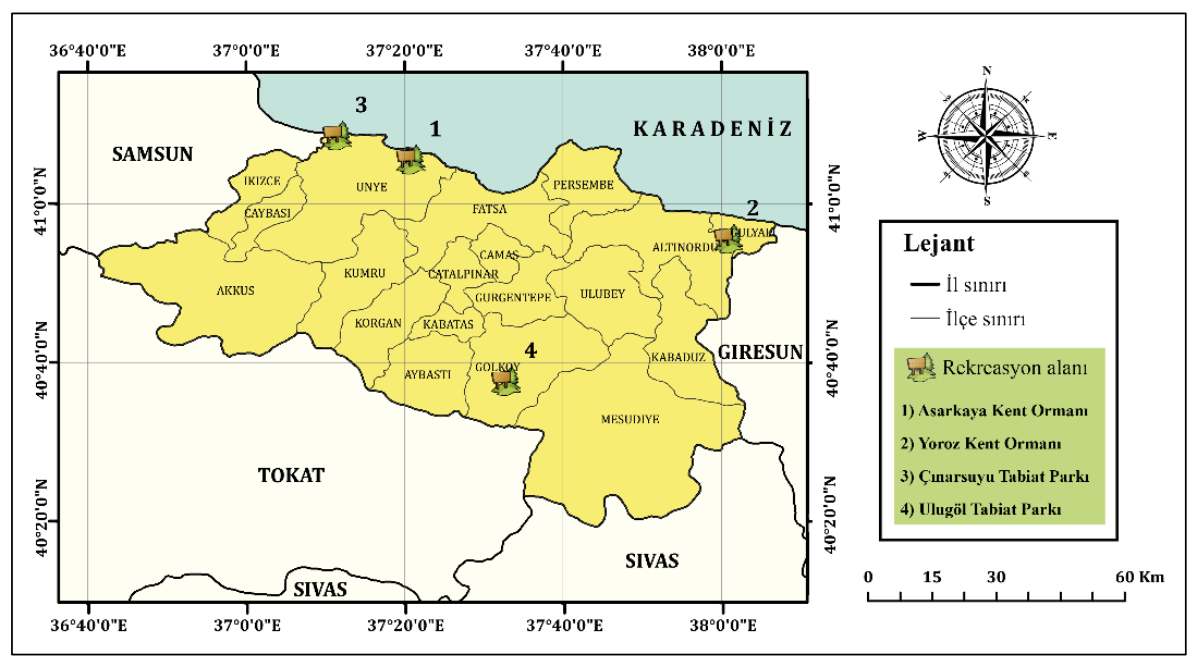

Görsel 1. Çalışma alanının konumu

İlde, kent ormanı statüsünde 3 alan (Asarkaya K.O., Yoroz K.O., Aybastı K.O.), tabiat parkı statüsünde ise 2 alan (Ulugöl T.P., Çınarsuyu T.P.) bulunmaktadır. Sosyal medya platformlarında, Aybastı Kent Ormanı ile ilgili yeterli veri elde edilemediğinden çalışma kapsamına alınmamıştır. Çalışmada değerlendirilen rekreasyon alanlarıyla ile ilgili genel bilgiler Görsel 2'de verilmiștir.

\begin{tabular}{ccccc}
\hline No & Rekreasyon alanı & İlçe & Büyüklük (ha) & Koordinat (UTM) \\
\hline 1 & Asarkaya Kent Ormanı & Ünye & 44.0 & 37T - D: 361155.72 - K: 4550478.71 \\
\hline 2 & Yoroz Kent Ormanı & Altınordu & 32.0 & 37T - D: 417386.79 - K: 4531554.37 \\
\hline 3 & Çnarsuyu Tabiat Parkı & Ünye & 6.7 & 37T - D: 348264.19 - K: 4556299.13 \\
\hline 4 & Ulugöl Tabiat Parkı & Gölköy & 26.5 & 37T - D: 377041.92 - K: 4498519.53 \\
\hline
\end{tabular}

Görsel 2. Rekreasyon alanlarına ait bilgiler

Sosyal medya platformları üzerinden 2012 yılı ve sonrasında konum belirtilerek ya da mekânı tanımlayıcı etiket kullanılarak paylaşılan 8.205 fotoğraf değerlendirilmiştir. Konum belirtilmeden 
paylaşılan fotoğraflar için "hashtag" adı verilen etiketler taranmıştır. Çalışmada, fotoğrafların paylaşım zamanı önemli olduğundan "tbt" olarak bilinen geçmiş tarihli fotoğraflar elenmiş ve değerlendirme dışı tutulmuştur. Elde edilen fotoğraf paylaşımlarının yoğunlaştığı zaman aralıkları ay ve mevsim düzeyinde belirlenmiștir. Ziyaretçiler tarafından çekilen fotoğraflardaki baskın unsurların neler olduğu ve ziyaretçilerin fotoğraf çekiminde hangi yöntemi daha fazla tercih ettiği ortaya konulmuştur. Elde edilen fotoğraflarda ön plana çıan unsurlar; "bitki örtüsü", "su yüzeyi", "bitki örtüsü ve su yüzeyi", "panoramik manzara", "sonbahar renklenmesi", "kar örtüsü", "evcilyabani hayvan", "yapılar ve tesisler" ile "çeşitli aktiviteler" olarak toplam 9 sınıfta toplanmıștır. Ziyaretçiler tarafından paylaşılan fotoğraflarda kullanılan çekim yöntemleri; "özçekim", "tekil fotoğraf" ve "grup fotoğrafi" olmak üzere 3 sınıfa ayrılmıștır.

Rekreasyon alanlarının sosyal medya bilinirliğini kantitatif olarak ortaya koymak amacıyla yorum, beğeni, tavsiye ve konum bildirimi (check-in) gibi etkileşim sayıları ortaya çıkarılmıştır. Ayrıca Instagram üzerinden rekreasyon alanlarında belirli etiketler (hashtag) kullanılarak yapılan paylaşımların sayıları belirlenmiştir. Ziyaretçilerin rekreasyon alanlarıyla ilgili görüş, öneri ve şikâyetlerini tespit etmek amacıyla Google Maps ve Foursquare platformlarından toplam 2.646 olumlu ve olumsuz yorum toplanmıștır. Ziyaretçilerin rekreasyon alanlarını olumlu anlamda nasıl hissettikleri, bu alanlarla ilgili hangi ifadeleri kullandıkları belirlenmiştir. Ayrıca yapılan olumsuz yorumlar esas alınarak ziyaretçilerin alanlarla ilgili şikâyet ettikleri unsurların neler olduğu tespit edilmiştir. Analizlerin doğruluğunu sağlamak amacıyla aynı kişiler tarafından paylaşılan tekrarlı yorumlar değerlendirme dişı tutulmuştur.

\section{Bulgular}

\section{Rekreasyon Alanlarının Sosyal Medya Bilinirliği}

Sosyal medya platformlarında paylaşılan gönderi sayıları ile mekânlar için yapılan yorum, beğeni ve yer bildirimi gibi etkileşim oranları o mekânların sosyal medyadaki popülaritesi hakkında önemli bilgiler vermektedir. Dört rekreasyon alanının; Google Maps, Facebook, Foursquare ve Instagram'daki etkileşim oranları Görsel 3'te verilmiştir. Asarkaya Kent Ormanı, Ulugöl Tabiat Parkı ve Çınarsuyu Tabiat Parkı'nda Facebook etkileşim oranı en fazla iken Yoroz Kent Ormanı'nda Google Maps ve Instagram etkileşim oranları diğer sosyal medya platformlarına göre daha fazladır. Dört rekreasyon alanı için de Foursquare etkileşim oranları en düşük durumdadır. Foursquare uygulamasının diğer platformlara göre daha az popüler olması sonucunda, yapılan etkileşimlerin oranı da buna paralel olarak düşük bulunmuştur (Görsel 3).

\begin{tabular}{cccccc}
\hline Rekreasyon alanı & $\begin{array}{c}\text { Google Maps } \\
\text { etkileşim oranı }\end{array}$ & $\begin{array}{c}\text { Foursquare } \\
\text { etkileşim oranı }\end{array}$ & $\begin{array}{c}\text { Facebook } \\
\text { etkileşim oranı }\end{array}$ & $\begin{array}{c}\text { Instagram } \\
\text { etkileşim oranı }\end{array}$ & Toplam (\%) \\
\hline Asarkaya K.O. & 26.9 & 15.8 & $\mathbf{2 9 . 4}$ & 27.9 & $\mathbf{1 0 0 . 0}$ \\
\hline Yoroz K.O. & $\mathbf{3 0 . 9}$ & 17.0 & 21.2 & $\mathbf{3 0 . 9}$ & $\mathbf{1 0 0 . 0}$ \\
\hline Ulugöl T.P. & 29.8 & 14.4 & $\mathbf{3 7 . 0}$ & 18.8 & $\mathbf{1 0 0 . 0}$ \\
\hline Çnarsuyu T.P. & 25.9 & 14.0 & $\mathbf{3 2 . 7}$ & 27.3 & $\mathbf{1 0 0 . 0}$ \\
\hline
\end{tabular}

Görsel 3. Rekreasyon alanlarının sosyal medyadaki etkileşim oranları

Instagram'da, rekreasyon alanlarını tanımlayan çeşitli etiketler kullanılarak paylaşılan gönderi sayıları Görsel 4'te verilmiştir. Gönderi sayılarına bakıldığında; dört rekreasyon alanı içinde en fazla gönderinin “\#ulugöl” etiketi ile Ulugöl Tabiat Parkı'nda paylaşıldığı görülmektedir. Ayrıca "\#ulugöltabiatparkı" ve "\#ulugol" etiketleri ile 1.000'in üzerinde gönderi paylaşılmıştır. Gönderi sayılarına göre ikinci sırada gelen Yoroz Kent Ormanı'nda “\#yoroz" etiketi ile 5.000'in üzerinden gönderi paylaşılmıştır. Asarkaya Kent Ormanı'nda ise "\#asarkaya" etiketi ile 1.000'in üzerinde gönderinin paylaşıldığı görülmektedir. Dört rekreasyon alanı içinde en az gönderi paylaşılan alan Çınarsuyu Tabiat Parkı'dır. Burada "\#çınarsuyu”, “\#cinarsuyu”, “\#unyecinarsuyu” gibi etiketler kullanılarak 100'e yakın gönderi paylaşılmıştır (Görsel 4).

\begin{tabular}{cccc}
\hline Asarkaya K.0. & Gönderi sayısı & Yoroz K.0. & Gönderi sayısı \\
\hline \#asarkaya & $1.000+$ & \#yoroz & $5.000+$ \\
\hline \#asarkayakentormanı & $100+$ & \#yoroztepesi & $1.000+$ \\
\hline
\end{tabular}




\begin{tabular}{cccc} 
\#asarkayakentormani & $100-$ & \#yorozkentormanı & $100+$ \\
\hline \#asarkayamilliparkı & $100-$ & \#yorozzirve & $100+$ \\
\hline \#ünyeasarkaya & $100-$ & \#orduyoroz & $100-$ \\
\hline Çınarsuyu T.P. & Gönderi sayısı & Ulugöl T.P. & Gönderi sayısı \\
\hline \#çınarsuyu & $100-$ & \#ulugöl & $16.600+$ \\
\hline \#cinarsuyu & $100-$ & \#ulugöltabiatparkı & $1.000+$ \\
\hline \#unyecinarsuyu & $100-$ & \#ulugol & $1.000+$ \\
\hline \#ünyeçınarsuyukamping & $100-$ & \#orduulugöl & $100+$ \\
\hline \#çınarsuyukampalanı & $100-$ & \#ulugölordu & $100-$ \\
\hline
\end{tabular}

Görsel 4. Rekreasyon alanlarında çekilen ve Instagram'da çeşitli etiketler ile paylaşılan gönderi sayıları

\section{Rekreasyon Alanlarının Kullanımında Zamansal Tercihler}

Sosyal medya içeriklerinin paylaşım zamanları esas alınarak oluşturulan, rekreasyon alanlarının kullanılmasında zamansal tercihler aylara göre Görsel 5'te, mevsimlere göre tercihler ise Görsel 6'da verilmiştir. Asarkaya Kent Ormanı konumu belirtilerek paylaşılan fotoğrafların zirveye ulaştığı ay; Foursquare ve Instagram paylaşımlarına göre temmuz ayı, Facebook ve Google Maps paylaşımlarına göre ise ağustos ayıdır. En az paylaşımın yapıldı̆̆ı ay Instagram, Foursquare ve Facebook verilerine göre ocak ayı, Google Maps'e göre ise ekim ayıdır.

Yoroz Kent Ormanı'nda çekilen fotoğrafların en fazla paylaşıldığı aylar; Instagram ve Google Maps verilerine göre ağustos, Foursquare'a göre eylül ve Facebook'a göre ise mart ayıdır. Fotoğraf paylaşımlarının en az yapıldığı aylar ise; Foursquare verilerine göre şubat ve kasım ayları, Facebook paylaşımlarına göre haziran, Google Maps verilerine göre şubat ayıdır.

Çınarsuyu Tabiat Parkı'nda, Instagram ve Facebook paylaşımlarının en fazla yapıldı̆̆ı ay temmuz iken, Google Maps ve Foursquare verilerine göre ağustostur. Tabiat parkı içerisinde en az fotoğrafın çekildiği dönemler ise; Facebook'a göre kasım ve nisan ayları arasındaki dönem, Foursquare verilerine göre ocak ve ekim ayları, Instagram verilerine göre ise mayıs ayıdır (Görsel 5).

Konumu "Ulugöl Tabiat Parkı" olarak belirtilerek yapılan paylaşımların zirveye ulaştığı ay; Facebook ve Instagram'a göre kasım ayı, Google Maps ve Foursquare verilerine göre ise ağustos ayıdır. Alan içerisinde yapılan paylaşımların en az sayıda olduğu aylar; Instagram'a göre mart, Google Maps ve Foursquare'a göre şubat, Facebook'a göre ise ocak ayıdır (Görsel 5).

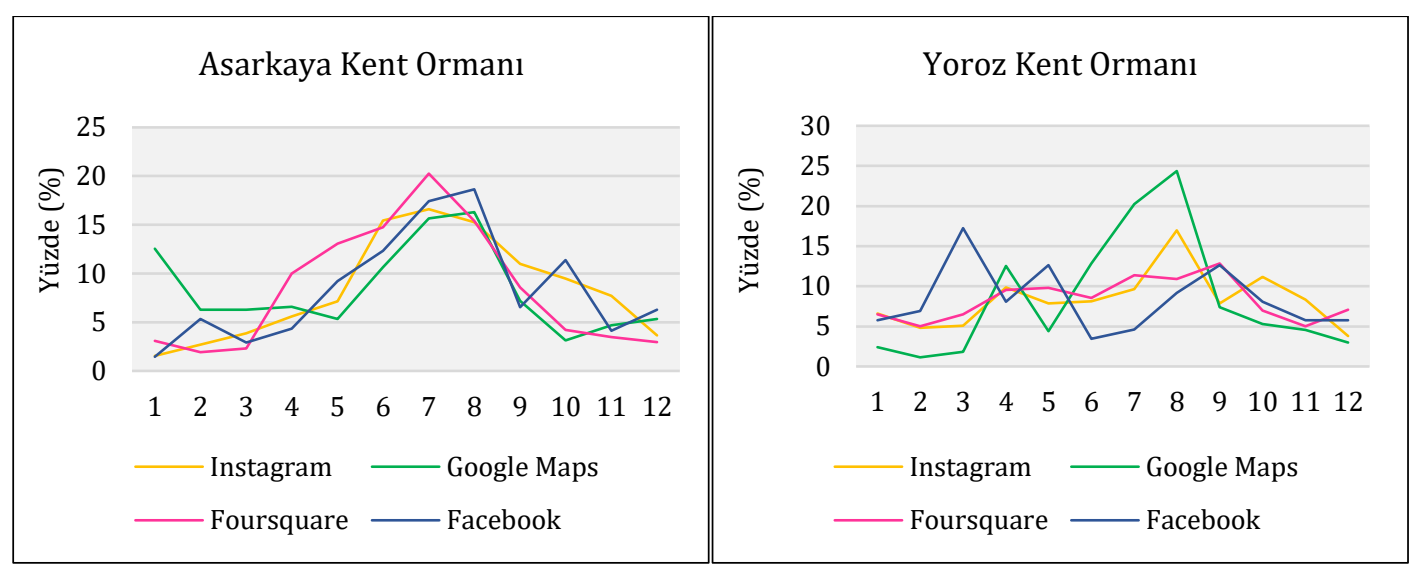




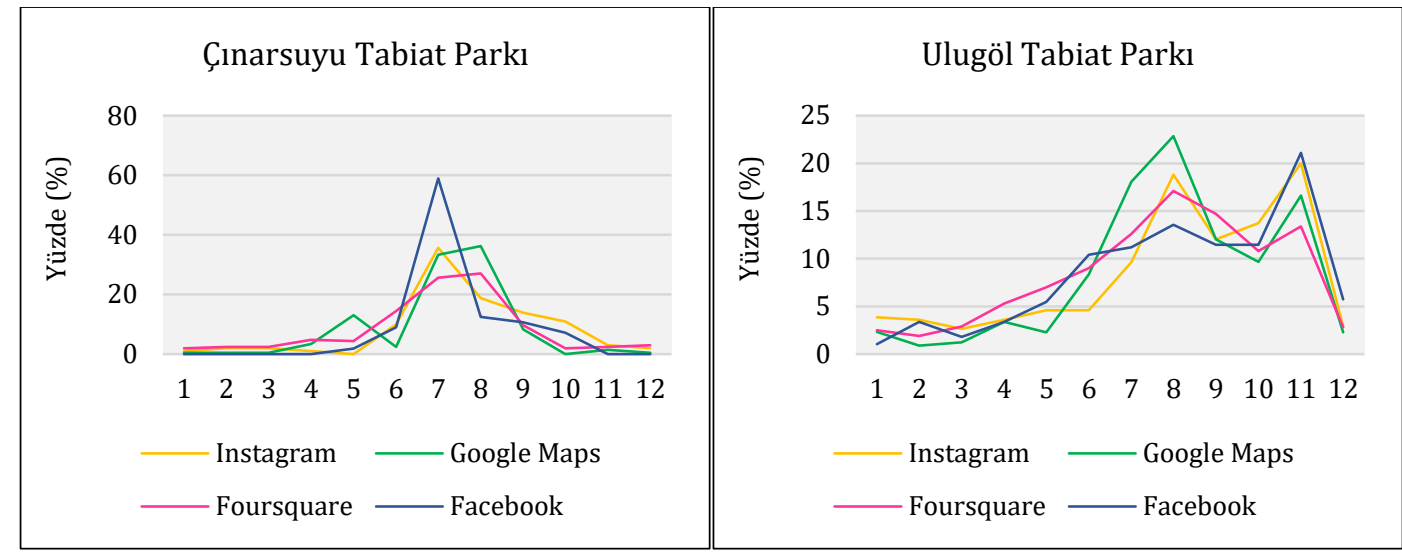

Görsel 5. Sosyal medya platformlarında yapılan paylaşımların aylara göre dağılımı

Çınarsuyu Tabiat Parkı ve Asarkaya Kent Ormanı'nda yapılan paylaşımlar, tüm sosyal medya platformlarına göre yaz aylarında zirveye ulaşmaktadır. Yoroz Kent Ormanı'nda ise yalnızca Facebook'a göre paylaşımların yoğunlaştı̆̆ı mevsim ilkbahardır. Ulugöl Tabiat Parkı'nda diğer rekreasyon alanlarından farklı olarak 2 sosyal medya platformuna (Facebook, Instagram) göre paylaşımların en fazla yapıldığı mevsim sonbahardır. Foursquare verilerine göre tabiat parkında yapılan paylaşımların oranı yaz ve sonbahar mevsimlerinde neredeyse eşit durumdadır. Google Maps verilerine göre tabiat parkında en fazla içerik paylaşımı yaz aylarında yapılmaktadır (Görsel 6).
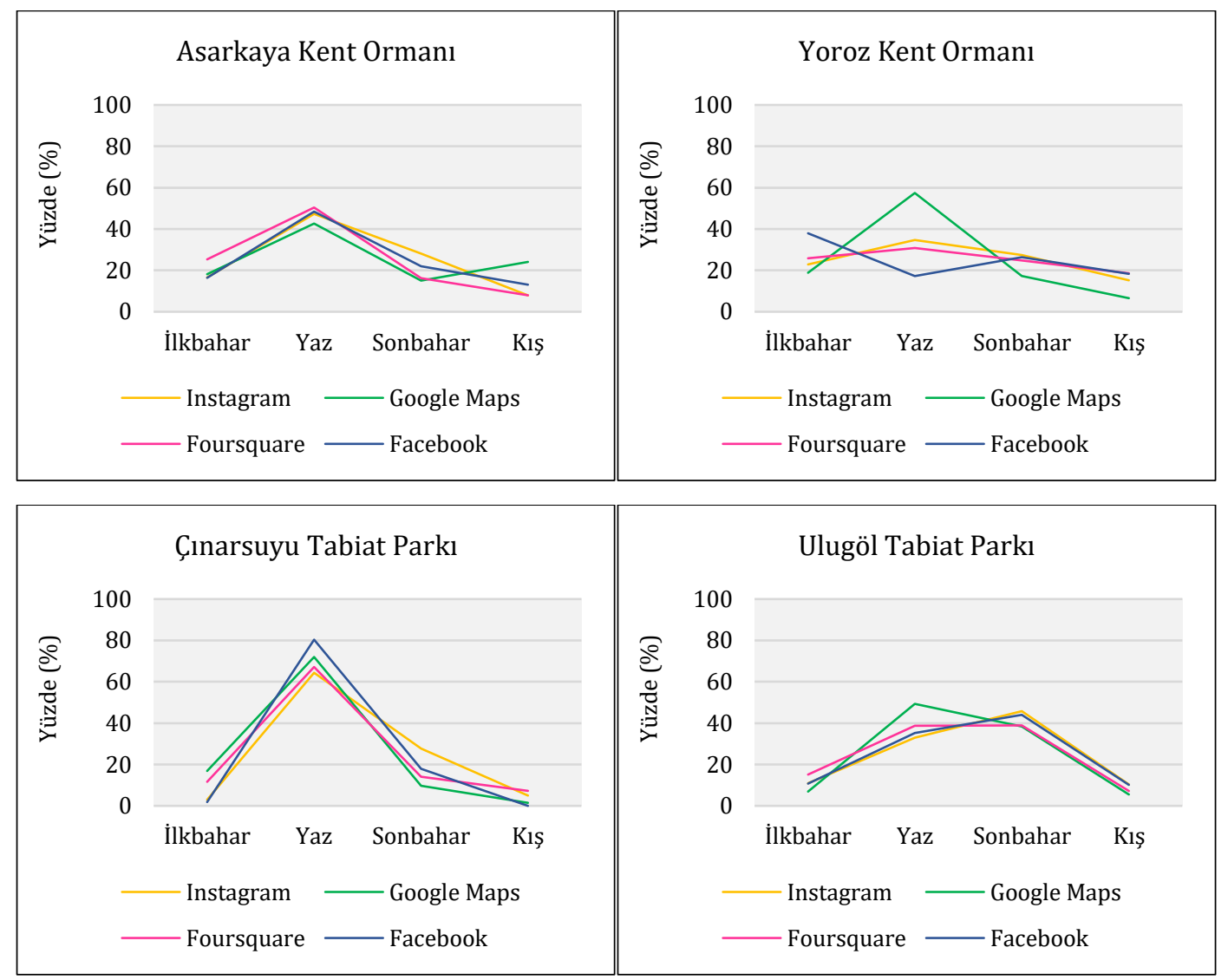

Görsel 6. Sosyal medya platformlarında yapılan paylaşımların mevsimlere göre dağılımı 


\section{Rekreasyon Alanı Ziyaretçilerinin Fotoğraf Çekim Tercihleri}

Rekreasyon alanlarını ziyaret eden insanların fotoğraf çekim tercihlerine bakıldığında (Görsel 7); Asarkaya Kent Ormanı'nda grup şeklinde çekilen fotoğrafların \%46.5 oranı ile daha fazla tercih edildiği görülmektedir. Aile ve arkadaş gruplarının piknik yapmak amacıyla Asarkaya Kent Ormanı'nı tercih etmesinin sonucu olarak, paylaşılan fotoğraflarda grup fotoğraflarının daha fazla ön plana çıktığı söylenebilir. Yoroz Kent Ormanı, Çınarsuyu Tabiat Parkı ve Ulugöl Tabiat Parkı'nda ise tekil fotoğrafların oranı özçekim ve grup fotoğraflarına göre daha fazladır. Özçekim fotoğraflarının oranı dört rekreasyon alanı içinde Çınarsuyu Tabiat Parkı'nda en yüksektir (\%30.6). Tekil fotoğrafların oranı ise Yoroz Kent Ormanı'nda en fazla durumdadır (Görsel 7).

\begin{tabular}{cccc}
\hline \multirow{2}{*}{ Fotoğraf çekim tercihi (\%) } & Tekil fotoğraf & Grup fotoğrafı \\
\hline Asarkaya K.O. & Özçekim & 31.8 & $\mathbf{4 6 . 5}$ \\
\hline Yoroz K.0. & 21.7 & $\mathbf{5 7 . 6}$ & 20.1 \\
\hline Çırsuyu T.P. & 22.3 & $\mathbf{4 6 . 9}$ & 22.4 \\
\hline Ulugöl T.P. & 30.6 & $\mathbf{4 5 . 2}$ & 36.3 \\
\hline
\end{tabular}

Görsel 7. Rekreasyon alanı ziyaretçilerinin fotoğraf çekim tercihleri

Rekreasyon alanlarında çekilen fotoğraflarda ön plana çıkan unsurların yüzde olarak dağılımları Görsel 8'de verilmiştir. Asarkaya ve Yoroz Kent Ormanı'nda fotoğraflanabilecek herhangi bir su yüzeyi bulunmadığından bu alanlarda "su yüzeyi" ve "bitki örtüsü + su yüzeyi" sinıfları değerlendirme dışı tutulmuştur. Asarkaya Kent Ormanı'nda çekilen fotoğraflarda en fazla ön plana çıkan unsurlar panoramik manzara (\%29.1), çeşitli aktiviteler (\%28.7) ve bitki örtüsüdür (\%21.7). Yoroz Kent Ormanı'nda da Asarkaya'da olduğu gibi panoramik manzara içerikli fotoğrafların oranı oldukça fazladır (\%61.3). Bunu bitki örtüsü (\%20.3) ve yapılar-tesisler (\%7.7) içerikli fotoğraflar takip etmektedir. Çınarsuyu Tabiat Parkı'nda çekilen fotoğraflarda denizin ön plana çıktığı fotoğrafların oranı \%31.8 ile en fazladır. Bununla birlikte çeşitli aktiviteleri içeren fotoğrafların oranı \%22.7'dir. Ulugöl Tabiat Parkı'nda su yüzeyi ve bitki örtüsünün birlikte ön plana çıktığı fotoğrafların oranı en fazladır (\%38.2). Bunu sırasıyla; sonbahar renklenmesi (\%17.4), bitki örtüsü (\%17) ve yapılar-tesisler (\%14.3) içerikli fotoğraflar izlemektedir (Görsel 8).

\begin{tabular}{|c|c|c|c|c|}
\hline Fotoğraflarda ön plana çıkan unsur (\%) & $\begin{array}{l}\text { Asarkaya } \\
\text { K.0. }\end{array}$ & $\begin{array}{l}\text { Yoroz } \\
\text { K.0. }\end{array}$ & $\begin{array}{l}\text { Çınarsuyu } \\
\text { T.P. }\end{array}$ & $\begin{array}{l}\text { Ulugöl } \\
\text { T.P. }\end{array}$ \\
\hline Bitki örtüsü (ağaç, çalı vb.) & 21.7 & 20.3 & 13.6 & 17.0 \\
\hline Su yüzeyi (deniz, göl vb.) & - & - & 31.8 & 5.4 \\
\hline Bitki örtüsü + su yüzeyi & - & - & 8.2 & 38.2 \\
\hline Panoramik manzara & 29.1 & 61.3 & 0.0 & 1.2 \\
\hline Sonbahar renklenmesi & 10.5 & 1.1 & 0.0 & 17.4 \\
\hline Kar örtüsü & 0.4 & 5.7 & 0.9 & 5.0 \\
\hline Evcil-yabani hayvan & 4.3 & 0.4 & 5.5 & 0.8 \\
\hline Yapılar ve tesisler (bina, duvar, merdiven vb.) & 5.4 & 7.7 & 17.3 & 14.3 \\
\hline $\begin{array}{c}\text { Çeşitli aktiviteler (yeme-içme, kamp, salıncak } \\
\text { vb.) }\end{array}$ & 28.7 & 3.4 & 22.7 & 0.8 \\
\hline
\end{tabular}




\begin{tabular}{ccccc}
\hline Toplam & 100.0 & 100.0 & 100.0 & 100.0 \\
\hline
\end{tabular}

Görsel 8. Fotoğraflarda ön plana çıkan unsurların dağlımı

\section{Ziyaretçilerin Rekreasyon Alanları ile İlgili Görüş, Öneri ve Şikâyetleri}

Ziyaretçiler tarafından rekreasyon alanları ile ilgili yapılan olumlu ve memnuniyet içeren yorumlar Görsel 9'da verilmiştir. Asarkaya Kent Ormanı için yapılan yorumlarda ziyaretçilerin; mangal, semaver ve et satışı gibi hizmetlerin fiyatlarını gayet uygun bulduğu görülmüştür. Kent ormanı ziyaretçiler tarafından ferah, havadar ve serin bir mekân olarak tanımlanmıştır. Yapılan yorumlarda, kent ormanında yapılabilecek en iyi aktiviteler olarak piknik, kuş gözlemciliği ve doğa yürüyüşü ön plana çıkmaktadır.

Yoroz Kent Ormanı, ziyaretçiler tarafından yapılan yorumlarda "doğa harikası", "saklı cennet", "oksijeni bol" ve "şehrin gürültüsünden uzak" gibi ifadeler ile tanımlanmıştır. Kent ormanına adını veren Yoroz Zirvesi'nin ve zirveye çıkan patika yolun ziyaretçiler tarafından oldukça ilgi gördüğü yorumlardan anlaşılmaktadır.

Çınarsuyu Tabiat Parkı ile ilgili yapılan yorumlarda burası "mavi ile yeșilin buluştuğu nokta" olarak tarif edilmiştir. Tabiat parkı; konumu itibariyle Ünye ilçe merkezine yakın olma ve ziyaretçilere hem denizi kullanma hem de piknik, kamp vb. etkinliklere olanak tanıma gibi özellikleri ile ziyaretçilerin beğenisini kazanmıştır. Bu sebeple, ziyaretçiler yaptıkları yorumlarda tabiat parkını "görülmeye değer" olarak nitelendirmiştir.

Ziyaretçiler, Ulugöl Tabiat Parkı'na adını veren ve bir krater gölü olan Ulugöl'ü “doğa harikası" olarak nitelendirmiştir. Farklı açılardan sunduğu çeşitli manzaralar ile göl etrafındaki parkurda yürüyüș yapmak, ziyaretçilerin en fazla tercih ettiği ve yorumlarda potansiyel ziyaretçilere tavsiye ettiği aktivite olmuştur. Ayrıca ziyaretçiler, göl üzerinde bulunan nilüfer ve diğer su bitkilerinin yaz aylarında özellikle görülmeye değer olduğunu vurgulamışlardır. Sonbahar aylarında göl etrafındaki bitki örtüsünde meydana gelen renk değişimi ve sonrasında yaşanan yaprak dökümü ziyaretçilerin en fazla rağbet ettiği, diğer sosyal medya kullanıcıları ile paylaştıkları yorumlar olmuştur (Görsel 9).

\begin{tabular}{|c|c|}
\hline Rekreasyon alanı & Yapılan olumlu yorumlar \\
\hline \multirow{9}{*}{ Asarkaya K.O. } & Fiyatlar gayet makul \\
\hline & Eşsiz manzara ve temiz hava \\
\hline & Ferah bir ortam \\
\hline & Yaz mevsiminde çok serin bir yer \\
\hline & Muhteşem bir doğa harikası \\
\hline & Yemyeșil geniş bir alan \\
\hline & Piknik için muhteşem bir yer \\
\hline & Oldukça havadar bir yer \\
\hline & Kuş gözlemciliği ve doğa yürüyüşü için ideal \\
\hline \multirow{9}{*}{ Yoroz K.O. } & Zirve muhteşem \\
\hline & Eşsiz bir manzara \\
\hline & Doğayla iç içe \\
\hline & Huzur dolu \\
\hline & Doğa harikası \\
\hline & Saklı bir cennet \\
\hline & Şehrin gürültüsünden uzak \\
\hline & Doğa yürüyüșünü sevenler için harika \\
\hline & Oksijeni bol \\
\hline \multirow{6}{*}{ Çınarsuyu T.P. } & Sessiz, sakin ve huzurlu bir mekân \\
\hline & Mavi ve yeşilin bir arada olduğu yer \\
\hline & Bir doğa harikası \\
\hline & Yaşanılacak yer \\
\hline & Çok güzel bir yer \\
\hline & Aile için oldukça uygun bir yer \\
\hline
\end{tabular}


Denize sıfır

\begin{tabular}{|c|c|}
\hline & Denize sıfır \\
\hline & Görülmeye değer \\
\hline & Güzel bir mesire yeri \\
\hline \multirow{9}{*}{ Ulugöl T.P. } & Harika bir manzarası var \\
\hline & Bağımlılık yapan bir yer \\
\hline & Göl etrafında yürüyüş için ideal bir yer \\
\hline & Tam bir doğal yaşam merkezi \\
\hline & Yaprak dökümü zamanı harikadır \\
\hline & Görülmesi gereken bir yer \\
\hline & Doğa harikası \\
\hline & Temmuzda nilüferler müthiș güzel \\
\hline & Şehrin gürültüsünden uzak bir yer \\
\hline
\end{tabular}

Görsel 9. Ziyaretçilerin rekreasyon alanları ile ilgili yaptıkları olumlu yorumlar

Rekreasyon alanlarını ziyaret eden ve bu alanlardaki deneyimlerini sosyal medya aracılığı ile diğer insanlara aktaran kullanıcıların yorumlarından elde edilen şikâyetler Görsel 10'da verilmiştir. Asarkaya Kent Ormanı ziyaretçilerinin şikayetçi oldukları konular; özellikle yaz aylarında kullanım talebinin artması ile aşırı bir kalabalı̆̆ın oluşması, kent ormanına giden yolların yüzeyinde bozukluklar olması, yapılan yol çalışmaları sebebiyle araç geçişlerinde havaya toz partiküllerinin kalkması, kent ormanı içerisindeki çevre düzenlemelerinin yetersiz olması, piknik masalarının alan içerisinde homojen dağılmaması ve tuvaletlerin temizlik yönünden zayıf olmasıdır.

Yapılan yorumlarda Yoroz Kent Ormanı'nda bulunan işletmenin her zaman hizmet vermediği ve kent ormanının yönlendirme levhaları yönünden yetersiz olduğu sonucuna varılmıştır. Ayrıca Yoroz Kent Ormanı için oldukça önemli olan orman içi yürüyüş parkuru ve parkur boyunca birçok sorunun da olduğu yorumlarda yer almaktadır. Zirveye çıkan yol üzerindeki ahşap basamakların bakımsız ve yıpranmış olması, yolun etrafında çöplerin bulunması ve orman içi yol ile ulaşılan zirvedeki seyir alanının oldukça küçük olması kent ormanındaki başlıca şikâyet edilen konulardır (Görsel 10).

Çınarsuyu Tabiat Parkı ziyaretçilerinin yaptığı yorumlarda en fazla şikâyetçi oldukları konular; park yönetimi ile iletişimde problem yaşanması, tabiat parkı personelinin ziyaretçilere ilgisiz davranması, park içerisinde çok sayıda başıboş köpeğin bulunması, tuvalet ve duşların temizliğinin yetersiz olması, parkın yakın çevresinde alışveriş yapılabilecek bir marketin yer almaması şeklindedir. Ayrıca, parkın kumsal bölümünde çöplerin bulunması, soyunma kabinlerinin temiz olmaması, karavanlar için temiz su-atık su konusunda problemler yaşanması ve bazı dönemlerde denizin dalgalı olması da diğer şikâyet edilen konulardandır.

İldeki en önemli rekreasyon alanlarından biri olan Ulugöl Tabiat Parkı'nı ziyaret edenlerin en fazla şikâyetçi olduğu konular ise; kent merkezinden parka giden güzergâh üzerinde yol yapımı çalışmaları nedeniyle ulaşımın oldukça zor olması, gölün etrafındaki alanlarda çöplerin bulunması, özellikle hafta sonu insan yoğunluğunun çok fazla olması, alandaki bazı piknik masalarının kırık olması, tuvaletlerin temizliğine dikkat edilmemesi, yoğun dönemlerde araç otoparkının yetersiz kalması, akşam saatlerinde park içerisindeki köpek sayısının artması ve özellikle yabancı turistler için alan tanıtımının yetersiz olmasıdır (Görsel 10).

Rekreasyon alanlarının fiziksel, çevresel ve konumsal farklılıklarından kaynaklı, ziyaretçilerin amaçları ile ilişkili olarak olumlu ve olumsuz görüşlerde farklılaşmalar görülmektedir.

\begin{tabular}{|c|c|}
\hline Rekreasyon alanı & Ziyaretçilerin alanlarla ilgili yaptıkları şikâyetler \\
\hline \multirow{6}{*}{ Asarkaya K.o. } & Așırı kalabalık olması \\
\hline & Kent ormanına giden yolların bozuk olması \\
\hline & Yol çalıșmaları nedeni ile havaya toz kalkması \\
\hline & Çevre düzenlemelerinin yeterli olmaması \\
\hline & Piknik masalarının alan içerisinde homojen dağılmaması \\
\hline & Tuvaletlerin temizlik yönünden zayıf olması \\
\hline \multirow{6}{*}{ Yoroz K.O. } & Yönlendirme bakımından eksik olması \\
\hline & Zirveye çıkan basamakların yıpranmıș ve bakımsız durumda olması \\
\hline & Zirvedeki seyir alanının oldukça dar olması \\
\hline & Zirvede bulunan ahşap seyir platformunun çürümüş durumda olması \\
\hline & Mevcut işletmenin her zaman hizmet vermemesi \\
\hline & Zirveye çıkan yol üzerinde çok fazla çöp bulunması \\
\hline
\end{tabular}


Zirveye çıkan yol üzerinde kaygan bölümlerin bulunması

Zirvede güvenli bir cam teras benzeri yapının bulunmaması

Park yönetimi ile rezervasyon amacıyla iletişim kurulamaması

Tabiat parkı personelinin ilgisiz davranması

Alanda çok sayıda başıboş köpeğin bulunması

Tuvalet ve duşların temizliğinin yeterli olmaması

Çınarsuyu T.P.

Yakın çevrede alışveriș yapılabilecek bir marketin bulunmaması

Parkın kumsal bölümünde plastik atıkların bulunması

Soyunma kabinlerinin yeterince temiz olmaması

Karavanlar için temiz su ve atık su konusunda problemler yaşanması

Bazı dönemlerde denizin dalgalı ve bulanık olması

Girişin ücretli olmasına rağmen temizlik konusunda sorunların bulunması

Yol yapımı çalışmaları nedeniyle ulaşımın oldukça zor olması

Gölün bazı kısımlarında ambalaj, izmarit gibi çöplerin bulunması

Özellikle hafta sonu oldukça kalabalık olması

Ulugöl T.P.

Piknik masalarından bazılarının kırık olması

Tuvaletlerin temizliğine yeterince dikkat edilmemesi

Yoğun ziyaret dönemlerinde otoparkın yetersiz kalması

Akşam saatlerinde park içerisindeki köpek sayısının artması

Özellikle yabancı turistler için tanıtımın yeterli düzeyde olmaması

Görsel 10. Ziyaretçilerin rekreasyon alanları ile ilgili yaptıkları şikâyet içerikli yorumlar

\section{Sonuç ve Öneriler}

Sosyal medya platformlarında gerçekleșen paylaşım, yorum ve beğeni gibi etkileşimlerin oranlarına bakıldığında; Ulugöl Tabiat Parkı'nın sosyal medya popülaritesinin diğer alanlara göre daha fazla olduğu sonucu ortaya çıkmaktadır. Tabiat parkında göl ve bitki örtüsünün bütünlük oluşturduğu çok sayıda fotoğraf paylaşılmıștır. Sosyal medyadaki bilinirliği anlamında ikinci sırada gelen rekreasyon alanı Yoroz Kent Ormanı'dır. Kent ormanı sınırları içinde bulunan ve yaklaşık 835 metre rakımlı zirve, ziyaretçilere panoramik bir manzara sunduğundan, özellikle ilkbahar ve yaz aylarında yoğun talep görmektedir. Bu alanda çekilen fotoğrafların büyük çoğunluğu panoramik manzara içerikli fotoğraflardır. Sosyal medya etkileşimlerine göre, dört rekreasyon alanı içerisinde en az bilineni ise Çınarsuyu Tabiat Parkı'dır. Bu durumun temel sebebi olarak; tanıtım eksikliği, tabiat parkının Ordu kent merkezine uzak olması ve bunun sonucunda daha kısıtlı bir kitleye hitap etmesi gösterilebilir. Ayrıca kent merkezi ve çevresinde; denize girme, piknik yapma gibi etkinliklerin gerçekleştirilebileceği pek çok alternatif noktanın bulunması ve ulaşım mesafesinin fazla olması Çınarsuyu Tabiat Parkı'nı dezavantajlı bir konuma getirmektedir.

Ulugöl Tabiat Parkı'nda diğer üç rekreasyon alanının aksine Kasım ayında önemli düzeyde bir ziyaret söz konusudur. Bu durumun oluşmasında, özellikle Kasım ayının ortalarından itibaren bitki örtüsündeki belirginleșen sonbahar renklenmesinin etkili olduğu düşünülmektedir. Tabiat parkındaki renklenmeyi görmek amacıyla, neredeyse yaz dönemindeki kadar ziyaretçi buraya gelmektedir. Ziyaretçilere görsel bir şölen sunan sonbahar renklenmesinin fon oluşturduğu, çok sayıda fotoğrafın sosyal medya platformlarında paylaşılması bu olguyu desteklemektedir. Dört rekreasyon alanında da yaz kullanımında diğer aylara göre önemli artışlar bulunmaktadır. Türkiye'nin farklı şehirlerindeki rekreasyon alanlarında yapılan çalışmalarda da benzer sonuçlara ulaşılmıştır (Tolunay vd., 2004; Onsekiz ve Emür, 2008; Kurdoğlu ve Düzgüneş, 2011; Akyol ve Akbulut, 2017).

Yapılan bu çalışma; çeşitli statülerde rekreasyon alanlarındaki ziyaretçi tercihlerinin belirlenmesinde sosyal medya verilerinin, anket, yerinde gözlem gibi geleneksel veri toplama yöntemlerine bir alternatif olarak kullanılabildiğini göstermiştir. Ancak bu yöntem, bazı yönlerden anket ve bire bir ziyaretçi görüşmelerinde elde edilebilecek kadar detaylı veriler sağlamamaktadır. Örneğin; ziyaretçilerin geldiği şehirler, ziyaret sıklığı, meslek, eğitim durumu, medeni hal, ulaşımda tercih edilen yöntem, aylık gelir gibi değişkenler paylaşımlarda belirtilmediği sürece bilinememektedir. Bu anlamda klasik veri toplama yöntemleri ile birlikte kullanıldığında çok daha tamamlayıcı ve tatmin edici sonuçlar ortaya çıkacağı düşünülmektedir. 
Nicel araştırmalarda, araştırmanın yapıldığı dönemdeki gelişmeler ve toplumsal hayatta yaşanan değişimlerin, araştırmanın yöntemi ve çıktıları üzerinde önemli etkileri bulunmaktadır. Bu çalışma, dünyada "pandemi" olarak nitelendirilen bir sürecin yaşandığı ve yüz yüze iletişimlerin zorlaştığı bir dönemde yürütülmüştür. Klasik yöntemlere göre nispeten daha yeni olan bir yöntemin uygulandığı bu çalışmanın, literatüre önemli katkılar sunacağı düşünülmektedir. Ayrıca çalışma sonuçlarının, değerlendirilen rekreasyon alanlarını yöneten ve denetleyen kurumlara, ziyaretçilerin tercih ve beklentileri hakkında önemli bilgiler vereceği kanaatindeyiz. Böylece ilgili kurumlar tarafından rekreasyon alanlarında yapılacak iyileştirmeler ile ziyaretçilerin alandan memnuniyet düzeyleri artacak ve ziyaretçilere koruma-kullanma dengesi içerisinde sürdürülebilir bir rekreasyon olanağı sağlanabilecektir.

\section{Yazar Katkıları}

Çalışmaya; Yazar 1: \% 50, Yazar 2: \% 50 oranında katkı sağlamıştır.

\section{Kaynakça}

Akten, S., Gül, A. ve Akten, M. (2012). Korunan Doğal Alanlarda Kullanılabilecek Ziyaretçi Yönetim Modelleri ve Karşılaştırılması. SDÜ Orman Fakültesi Dergisi, (13), 57-65.

Akyol, A. ve Akbulut, E. (2017). Korunan Alanların Planlanması ve Etkin Yönetiminde Ziyaretçi Özellikleri ve Algılarının Önemi: Kurşunlu Şelalesi Tabiat Parkı Örneği. Türkiye Ormancılık Dergisi, 18(3), 197-206.

Arat, T. ve Dursun, G. (2016). Seyahat ve Konaklama Tercihi Açısından Sosyal Paylaşım Sitelerinin Kullanımı. Selçuk Üniversitesi Sosyal Bilimler Meslek Yüksek Okulu Dergisi, (19), 111-128.

Arslan, E.S. ve Örücü, Ö.K. (2020). Kültürel Ekosistem Hizmetlerinin Sosyal Medya Fotoğrafları Kullanılarak Modellenmesi: Eskişehir Örneği. Türkiye Ormancılık Dergisi, 21(1), 94-105.

Clark, R. ve Stankey, G. (1979). The Recreation Opportunity Spectrum: A Framework for Planning, Management and Research. Washington DC: US Department of Agriculture and Forest Service.

Figueroa-Alfaro, R.W. ve Tang, Z. (2017). Evaluating The Aesthetic Value of Cultural Ecosystem Services by Mapping Geo-Tagged Photographs from Social Media Data on Panoramio and Flickr. Journal of Environmental Planning and Management, 60(2), 266-281.

Ghermandi, A., Camacho-Valdez, V. ve Trejo-Espinosa, H. (2020). Social Media-Based Analysis Of Cultural Ecosystem Services and Heritage Tourism in A Coastal Region of Mexico. Tourism Management, (77), 104002.

Göktuğ, T.H. ve Kurkut, G. (2016). Korunan Alanlarda Sürdürülebilir Ziyaretçi Yönetimi: Stratejiler ve Araçların İncelenmesi. Journal of Bartın Faculty of Forestry, 18(1), 118-131.

Hausmann, A., Toivonen, T., Slotow, R., Tenkanen, H., Moilanen, A., Heikinheimo, V. ve Di Minin, E. (2018). Social Media Data Can Be Used to Understand Tourists' Preferences for NatureBased Experiences in Protected Areas. A Journal of The Society for Conservation Biology. 11(1), E12343.

Heikinheimo, V., Minin, E.D., Tenkanen, H., Hausmann, A., Erkkonen, J. ve Toivonen, T. (2017). UserGenerated Geographic Information for Visitor Monitoring in A National Park: A Comparison of Social Media Data and Visitor Survey. ISPRS International Journal of Geo-information, 6(3), 85. 
Kurdoğlu, O. ve Düzgüneș, E. (2011). Artvin Kent Ormanının Rekreasyon Olanakları ve Kullanıcı Tercihlerinin İrdelenmesi. Artvin Çoruh Üniversitesi Orman Fakültesi Dergisi, 12(2), 199-210.

Lee, E., Lee, J. A., Moon, J. H. ve Sung, Y. (2015). Pictures Speak Louder Than Words: Motivations for Using Instagram. Cyberpsychology, Behavior, And Social Networking, 18(9), 552-556.

Mancini, F., Coghill, G.M. ve Lusseau, D. (2018). Using Social Media to Quantify Spatial and Temporal Dynamics of Nature-based Recreational Activities. Plos One, 13(7), E0200565.

Onsekiz, D. ve Emür, S.H. (2008). Kent Parklarında Kullanıcı Tercihleri ve Değerlendirme Ölçütlerinin Belirlenmesi. Erciyes Üniversitesi Sosyal Bilimler Enstitüsü Dergisi, 1(24), 69-105.

Öztürk, S., Kadak, M.K., Ayvadoğlu, S., Saat, A., Kütahyalı, E.Ö. ve Köleoğlu, Ö. (2019). Korunan Alan Kaynak Değerlerine İlişkin Ziyaretçi Tercihlerinin Sosyal Medya Verileri Kullanılarak Belirlenmesi. Karabük Üniversitesi Sosyal Bilimler Enstitüsü Dergisi, 9(2), 685-695.

Richards, D.R. ve Friess, D.A. (2015). A Rapid Indicator of Cultural Ecosystem Service Usage At A Fine Spatial Scale: Content Analysis of Social Media Photographs. Ecological Indicators. (53), 187195.

Richards, D.R. ve Tunçer, B. (2018). Using Image Recognition to Automate Assessment of Cultural Ecosystem Services from Social Media Photographs. Ecosystem Services, (31,) 318-325.

Sinclair, M., Mayer, M., Woltering, M. ve Ghermandi, A. (2020). Using Social Media to Estimate Visitor Provenance and Patterns of Recreation in Germany's National Parks. Journal of Environmental Management, (263), 110418.

Stankey, G.H., Cole, D.N., Lucas, RC., Petersen, M. E. ve Frissell, S.S. (1985). The Limits of Acceptable Change (LAC) System For Wilderness Planning. Ogden: Forest Service.

Tenkanen, H., Di Minin, E., Heikinheimo, V., Hausmann, A., Herbst, M., Kajala, L. ve Toivonen, T. (2017). Instagram, Flickr, or Twitter: Assessing The Usability of Social Media Data for Visitor Monitoring in Protected Areas. Scientific Reports, 7(1), 1-11.

Toivonen, T., Heikinheimo, V., Fink, C., Hausmann, A., Hiippala, T., Järv, O., Tenkanen, H. ve Di Minin, E. (2019). Social Media Data for Conservation Science: A Methodological Overview. Biological Conservation, (233), 298-315.

Tolunay, A., Alkan, H. ve Korkmaz, M. (2004). Isparta Tarihi Ayazmana Mesireliği'nin Açıkhava Rekreasyonu Açısından Kullanıcı Özellikleri. Süleyman Demirel Üniversitesi Fen Bilimleri Enstitüsü Dergisi, 8(1), 59-70.

TÜIK (2021). Türkiye İstatistik Kurumu. Erişim adresi http://www.tuik.gov.tr.

Walden-Schreiner, C., Leung, Y.F. ve Tateosian, L. (2018). Digital Footprints: Incorporating Crowdsourced Geographic Information for Protected Area Management. Applied Geography, (90), 44-54.

Wang, Y. (2015). Incorporating Social Media in Public Relations: A Synthesis of Social Media-related Public Relations Research. Public Relations Journal, 9(3), 1-14. 


We Are Social (2021). Digital 2020: Turkey Report. Erişim adresi
https://datareportal.com/reports/digital-2020-turkey.

Zhang, Z., Chen, R.J., ve Han, L.D. (2019). Strategic Sustainable Development Through the Lenses of Tourists' Preferences: A Geotagged Photo Approach. Journal of Sustainable Development, $12(3), 12-21$.

\section{Extended Abstract}

People living in the cities devote their free time to various recreational activities in order to eliminate the stress caused by the difficult urban life and to break monotony. With the increasing urban population, many more people need quality recreational activities that meet their expectations. For this reason, the demand for areas that offer a wide variety of recreational opportunities such as protected areas are increasing every day. As a result of intensive and unplanned recreation activities, the satisfaction level of the visitors from the recreation areas decreases. It is necessary to analyze the expectations of visitors in areas such as national parks, nature parks and urban forests that are managed with a delicate conservation-usage balance. The time spent on social media today constitutes an important part of people's daily life. Social media is a very large data source where various information on every subject is shared in addition to its communication and socialization functions. Although many traditional methods are followed for determining visitor preferences in recreation areas, using social media data for this purpose is a fairly new phenomenon. Geo-tagged photos and comments shared on social media provide important information about visitors' preferences.

The main purpose of the study is to determine of visitor preferences and trends in the recreation areas of Ordu in the light of social media data. The source of social media data is Facebook, Instagram, Google Maps and Foursquare contents. For the purpose of the study, four recreation areas were selected, two of which are urban forests and two of which have the status of nature parks. Then, 8,205 photos and 2,646 comments shared by specifying the location since 2012 have been evaluated. The popularity of recreation areas on social media platforms, temporal preferences in visiting recreation areas, photo shooting preferences, the prominent elements in the shared photographs, and the likes and complaints of the visitors about the areas have been revealed.

Considering the rates of interactions such as sharing, commenting, and liking on social media platforms; The result is that the social media popularity of Ulugöl Nature Park is higher than other areas. Numerous photographs were shared in the nature park, in which the lake and vegetation form an integrity. The second recreation area in terms of its awareness in social media is Yoroz Urban Forest. Located within the boundaries of the city forest and at an altitude of about 835 meters, the summit is in high demand especially in the spring and summer months, as it offers a panoramic view to the visitors. Most of the photographs taken in this area are panoramic views. According to social media interactions, the least known of the four recreation areas is Çinarsuyu Nature Park. As the main reason for this situation; lack of publicity, the fact that the nature park is far from Ordu city center and as a result, it appeals to a more limited audience. In addition, in the city center and its surroundings; Cinarsuyu Nature Park is in a disadvantageous position due to the fact that there are many alternative points where activities such as swimming and picnics can be held, and the distance of transportation is long.

The most prominent elements in the photographs taken in Asarkaya Urban Forest are panoramic view (29.1\%), various activities (28.7\%) and vegetation (21.7\%). In Yoroz Urban Forest, as in Asarkaya, the rate of photographs with panoramic scenery is quite high (61.3\%). This is followed by photographs containing vegetation (20.3\%) and buildings-facilities (7.7\%). In the photographs taken in Çinarsuyu Nature Park, the rate of photographs in which the sea stands out is the highest with $31.8 \%$. However, the rate of photos that include various activities is $22.7 \%$. The rate of photographs in which the water surface and vegetation stand out together is the highest (38.2\%) in the Ulugöl Nature Park. While Facebook interaction rate is highest in Asarkaya City Forest, Ulugöl Nature Park and C.narsuyu Nature Park, Google Maps and Instagram interaction rates are higher in Yoroz City Forest compared to other social media platforms. Foursquare interaction rates are the lowest for all four recreation areas. As the Foursquare application is less popular than other platforms, the rate of interactions was found to be low accordingly.

This study has shown that social media data can be used as an alternative to traditional data collection methods such as surveys and on-site observations in determining the visitor preferences in recreational areas of various statuses. However, this method does not provide enough detailed data in some ways that can be obtained from 
surveys and one-on-one visitor interviews. For example; the cities from which visitors come, frequency of visits, occupation, educational status, marital status, preferred method of transportation, monthly income cannot be known unless specified in the shares. In this sense, it is thought that when used together with classical data collection methods, much more complementary and satisfactory results will occur.

Social developments and changes experienced during the period of research have a significant impact on the method and outputs of the research. This study; it was conducted at a time when a process described as a "pandemic" was experienced and face-to-face communication was difficult. It is thought that this study, which uses a newer method compared to the classical methods, will make important contributions to the literature. In addition, we believe that the results of the study will provide important information about the preferences and expectations of the visitors to the institutions that manage and inspect the recreation areas evaluated. Thus, with the improvements to be made in the recreation areas by the relevant institutions, the satisfaction level of the visitors will increase and a sustainable recreation opportunity will be provided to the visitors in a balance of protection and use. 